\title{
Prevention Services via Public Long-term Care Insurance can be Effective Among a Specific Group of Older Adults: A City Claim Data Analysis
}

Tomoko Ito

University of Tsukuba https://orcid.org/0000-0003-1128-0194

Takahiro Mori ( $\square$ takahiromori@outlook.com )

Health Services Research and Development Center, University of Tsukuba https://orcid.org/0000-00030216-2284

Natsumi Shimafuji

Ridgelinez Limited

Katsuya lijima

The University of Tokyo

Satoru Yoshie

University of Tsukuba

Nanako Tamiya

University of Tsukuba

Research article

Keywords: Prevention services, Community care, Older adults, Long-term care insurance

Posted Date: October 5th, 2020

DOl: https://doi.org/10.21203/rs.3.rs-57448/v1

License: (c) (i) This work is licensed under a Creative Commons Attribution 4.0 International License.

Read Full License 


\section{Abstract}

\section{Background}

To evaluate the effects of prevention services provided by long-term care insurance (LTCI) for older adults who require support from $\mathrm{LTCl}$ in Kashiwa City, Japan

\section{Methods}

We conducted an analysis using the following population-based longitudinal data in Kashiwa City between April 2012 and March 2015: Data of National Health Insurance and LTCI claims, the survey for certification of $\mathrm{LTCl}$, the register, and premium tier classification. All data was linked using the preassigned anonymous identifying numbers. We analyzed the Cox regression model using the time for the deteriorations of long-term care levels as an outcome and the use of preventive care services as the primary exposure among participants aged 75 years or older, who had either support levels 1 or 2 at the beginning of this analysis. The study was further stratified by both age and initial support level.

\section{Results}

The final analysis included 1,289 participants. The primary result showed, among all participants, that preventive service was not effective (hazard ratio $0.96,95 \%$ confidence interval 0.78-1.19). In our subanalysis, the preventive service was effective in avoiding deteriorations only among those aged 85 and older with support level 1 (HR $0.65,95 \% \mathrm{Cl} 0.43-0.97$ ) out of four groups.

\section{Conclusions}

The preventive services of $\mathrm{LTCl}$ in Kashiwa City showed a significant effect on the deterioration among subjects aged 85 or older, whose disabled level were low (support level 1). Our results suggest that the prevention services provided by LTCI may not be effective for all older individuals; to provide these services efficiently, local governments, as insurers of $\mathrm{LTCl}$, will need to identify the specified groups that may benefit from the preventive services.

\section{Background}

Many societies are rapidly aging. Japan began to see a super-aging population earlier than other countries and is expected to see a peak in their aged population in $2025,{ }^{1}$ when one third of individuals in Japan will be aged over 65. In 2000, long-term care insurance (LTCI) was introduced in Japan to be used as a public insurance system to provide care for disabled older adults, both at home and in facilities. ${ }^{23}$ As Japanese society has had an increasing number of aging adults, the number of disabled people in LTCI has also increased greatly. In 2006, the number of individuals on LTCI had increased to 2.17 million, which is approximately $200 \%$ more from when the initiative was announced. ${ }^{4}$ In particular, increases in the numbers of people with mild disabilities was noticeable. In 2006, the government established 
prevention services designed to decrease the number of people becoming disabled. ${ }^{5}$ Prevention services include day care (rehabilitation), day services (support for daily living), and also visiting services. These services are arranged for each person based on an assessment of their disabilities. In the regular reforms, provision of prevention services was gradually left in the hands of local municipalities ${ }^{6}$ and offered prevention services may be changed or limited. Therefore, discussion is necessary to plan and implement future prevention services and determine how resources will be concentrated.

The effects of prevention services have been evaluated in several studies. Many showed the effects of specific programs such as muscle strength rehabilitation and locomotive function improvement programs. ${ }^{7-11}$ To evaluate the outcomes, these studies used specific physical functions such as the Timed Up Go test ${ }^{7-9} 1112$ or time standing on one leg. ${ }^{7-10}$ For discussing public health policies, indicators are expected to address items such as the level of certified care need in LTCI to be supported. However, few studies used that level as an outcome ${ }^{12-16}$ and their results were controversial. ${ }^{13-16}$

Therefore, we aimed to evaluate the effect of prevention services on disabled adults using the level of certified care need in LTCI. To offer further insight into resource investment, we showed the difference in the preventive effects on age and the initial certified level.

\section{Methods}

\section{Study design and data collection}

We conducted a population-based longitudinal analysis in Kashiwa City, Prefecture of Chiba, Japan. In this study, we used data of the National Health Insurance (NHI), LTCl claims, survey for certification of LTCl, registry, and insurance fee level for Kashiwa City A between April 2012 and March 2015. Kashiwa City is located in the Kanto region and has a population of 400,000 and an aging rate of $24.4 \%$, which is lower than the national average of $26.6 \%$ in 2015 . The survey for certification of $\mathrm{LTCl}$ collects items to determine the certification of $\mathrm{LTCl}$, and is conducted by a surveyor who is commissioned by the local government to visit the subject and observe them directly. This survey was conducted almost nationwide with some differences, and has been statistically processed. Each data was linked using the ID number assigned for the study. This individual linked dataset was used in some previous studies. ${ }^{17-20}$

The data was provided by Kashiwa City to the University of Tsukuba for research purposes, and the data provided and used for research purposes was approved by the Medical Ethical Review Board of University of Tsukuba (approved number 1448).

\section{Participants}

Participants were individuals who were 75 years old or older living in Kashiwa City and who first received the LTCI certification from July 2012 to March 2014. They were certified as support level 1 or 2 included in the study. Their status as a resident of Kashiwa City was confirmed from the Basic Resident Register data before the first certification that they required long-term care. In addition, in order to demonstrate 
that the use of preventive care services for six months after the initial certification was necessary, it was also confirmed that participants were both alive and had remained at support level 1 or 2 during the six months after their certification. Those who had been hospitalized during the 6 months were excluded. The degree to which individuals need LTCI services indicates their need for care in daily life; this relates to the amount of LTCI services and available services they will use. ${ }^{21}$ In 2006 , the certified levels for LTCI were revised and divided into seven categories: support level 1-2 and care level 1-5, with care level 5 requiring the most intense amount of care. ${ }^{5}$ The clinical picture of an individual requiring level 5 nursing care is almost bedridden. On the other hand, individuals with level 1 support can perform most of the basic activities of daily living on their own, but need to remain active to prevent the deterioration of their current state, increasing their need for nursing care. This category does require some support, though. Those who were certified as support level 2 require more assistance to complete activities of daily living, and some nursing care is also required. It is expected in the objective of the policy that their condition will remain the same or improve using LTCI services. ${ }^{6}$

\section{Outcome}

The outcome variable was the time (unit: days) from the date on which the participant first certified for LTCl use, for either support level 1 or 2, until their state deteriorated to care level 1 or greater. Care level 1 indicates the elderly who need more services than watching-over care, especially those with limited mobility. For those who did not show any deterioration, the end date of the validity period in their observed final certification of support level 1 or 2 was considered as the observation end date and censored. The Basic Resident Register data was also used to confirm that no participants had died or moved before the end of the observation period.

\section{Exposure}

Exposure was based on the use of preventive services for six months, including the first month when they were certified as the eligible LTCI user, which was designated as support level 1 or 2 . Those who used prevention services at least once were included in the exposure group. Long-term care prevention service is an $\mathrm{LTCl}$ service that can be used by those who have been identified as support level 1 or 2 and aims to ensure that the participant's independence in daily life does not deteriorate. The content of visiting care which include bathing, nursing, or outpatient care and rehabilitation. Coordination of preventive care services is performed by specialized staff commissioned by the local government. ${ }^{5}$ However, the use of the service is based on its need by an individual or their family, and the service will not be provided unless applied for. For this reason, it is predicted that the use of the service is influenced by individual characteristics including economic status, and it is necessary to adjust with covariates.

\section{Covariates}

Covariates were used to indicate subject severity. Covariates were set based on the use of medical services in the three months before the first certification month. The Charlson Comorbidity Index (CCl) 
scores calculated from the illness information included in the medical claim data was treated as a covariate. ${ }^{22}$ We used the revised $\mathrm{CCl}$ scores as validated for Japanese administrative data. ${ }^{23}$ In addition, the degree of independence in daily activities and in cognitive function shown in the survey data for LTCI certification were treated as covariates, and were found to be predictors of deterioration in the previous analysis. ${ }^{24}$ The degree of independence in daily activities or in cognitive function is widely used in Japan to evaluate the elderly activity (Appendix 1). These two indexes are created while the investigator objectively determines the degree of independence regarding the state of the elderly with disabilities at the care site. In the index for elderly daily activities evaluation, the judgment criteria are the following four levels: Rank J (living independently), Rank A (semi bedridden), Rank B (bedridden), and Rank C (bedridden). For our model, we defined the disabled status was dependent when the degree of independence in daily activities was Rank A or severer. On the other hand, the degree of independence in cognitive function includes nine stages of daily life independence of elderly people with dementia. The dependence for demented status in our model was defined dependent when that cognitive index was Rank $\otimes$ or more dependent. For covariates in the socio-economic situation, we used the insurance fee of LTCl. The fee level is calculated based on the taxation of the insured households, with tax-exempt households designated as low-income households. The previous study showed that income level influences service use. ${ }^{19}$

\section{Statistical analysis}

We showed the characteristics of participants among preventive services users and controls with statistical tests. Chi-square tests were performed on the binary variables and Wilcoxon's sum rank test were applied to the ordered variable (the $\mathrm{CCl}$ ). We drew the survival curves showing the deterioration from support level 1 or 2 to care level 1 or worse with Kaplan-Meier estimates. The differences of the curves were tested with log-rank tests. We analyzed the Cox regression model using the time from the first day of certification for LTCl to when the participant's condition had deteriorated to certified care level 1 or worse as an outcome variable. The exposure was the use of preventive care services, adjusted for covariates. Primary analysis was conducted in all subjects. These models were also tested in four groups categorized according to age $(<85,>=85)$ and the first support level (support level 1,2$)$ as sub-analysis. STATA Version 14.2 (Stata-Corp LLC, College Station, Texas, United States of America) was used for the analysis. The statistical significance level was a two-sided p-value of less than $5 \%$.

\section{Results}

The study subjects included 1,289 participants (Fig. 1), of which 578 participants (44.8\%) were preventive service users (Table 1). The number of users tends to be higher among women and participants with low household incomes. During the observation period, 348 (27.0\%) of all participants showed a deterioration in their certificated level to care level 1 or worse. The median time to deterioration was 212 days, with a minimum of 8 days and a maximum of 692 days. In the control group, the mean observation period was 522 days (standard deviation 266). 
Table 1

Characteristics of participants

\begin{tabular}{|c|c|c|c|c|c|c|c|}
\hline & & $\begin{array}{l}\text { Prev } \\
\text { user: }\end{array}$ & service & Cont & & All & \\
\hline & & $(n=5$ & & $(n=$ & & $\begin{array}{l}(n= \\
1,289\end{array}$ & \\
\hline & & $\mathrm{n}$ & $\%$ & $\mathrm{n}$ & $\%$ & $\mathrm{n}$ & $\begin{array}{l}p- \\
\text { value }\end{array}$ \\
\hline Age & $<85$ & 331 & 44.2 & 418 & 55.8 & 749 & 0.581 \\
\hline & $>=85$ & 247 & 45.7 & 293 & 54.3 & 540 & \\
\hline Sex & Male & 159 & 39.9 & 239 & 60.1 & 398 & 0.018 \\
\hline & Female & 419 & 47.0 & 472 & 53.0 & 891 & \\
\hline Certified level & $\begin{array}{l}\text { Support level } \\
1\end{array}$ & 354 & 41.9 & 490 & 58.1 & 844 & 0.004 \\
\hline & $\begin{array}{l}\text { Support level } \\
2\end{array}$ & 224 & 50.3 & 221 & 49.7 & 445 & \\
\hline Use of inpatient medical & Yes & 397 & 44.3 & 499 & 55.7 & 896 & 0.561 \\
\hline & No & 181 & 46.1 & 212 & 53.9 & 393 & \\
\hline Use of outpatient medical & Yes & 411 & 44.8 & 507 & 55.2 & 918 & 0.937 \\
\hline & No & 167 & 45.0 & 204 & 55.0 & 371 & \\
\hline Disabled status & Dependent & 221 & 46.4 & 255 & 53.6 & 476 & 0.381 \\
\hline & Independent & 357 & 43.9 & 456 & 56.1 & 813 & \\
\hline Demented status & Dependent & 108 & 44.8 & 133 & 55.2 & 241 & 0.992 \\
\hline & Independent & 470 & 44.8 & 578 & 55.2 & 1,048 & \\
\hline Household income & Low & 410 & 47.5 & 453 & 52.5 & 863 & 0.006 \\
\hline & $\begin{array}{l}\text { High and } \\
\text { Middle }\end{array}$ & 168 & 39.4 & 258 & 60.6 & 426 & \\
\hline $\begin{array}{l}\text { Charlson Comorbidity Index } \\
\text { scores }\end{array}$ & $=0$ & 184 & 43.7 & 237 & 56.3 & 421 & 0.843 \\
\hline & $>=1$ & 232 & 45.6 & 277 & 54.4 & 509 & \\
\hline & $>=3$ & 123 & 48.2 & 132 & 51.8 & 255 & \\
\hline & $>=5$ & 39 & 37.5 & 65 & 62.5 & 104 & \\
\hline
\end{tabular}




\begin{tabular}{|lll|}
\hline & $\begin{array}{l}\text { Preventive service Controls All } \\
\text { users }\end{array}$ \\
\hline * $\mathrm{p}$-value by Wilcoxon's sum rank test & & \\
\hline
\end{tabular}

According to the results of primary analysis using Cox regression model, the preventive service was not effective (hazard ratio $0.96,95 \%$ confidence interval 0.78-1.19) (Table 2). Older age (age $>=85$ ), more severely disabled (support level 2), and dependency for demented status were included as covariates in the Cox regression model and were significant factors of deterioration in the primary analysis. However, in the sub-analyses in which we performed Cox regression stratified by age and initial care need status, the preventive service showed effectiveness (hazard ratio $0.65,95 \%$ confidence interval $0.43-0.97$ ) in only one group (i.e., age > = 85 \& support level 1 ) of the four groups (Fig. 2). 
Table 2

Effects of preventive service to avoid deterioration to care level 1 or worse

\begin{tabular}{|c|c|c|c|}
\hline & & \multicolumn{2}{|c|}{ Adjusted } \\
\hline & & $\mathrm{HR}$ & $95 \% \mathrm{Cl}$ \\
\hline \multirow[t]{2}{*}{ Preventive service } & Use & 0.96 & $0.77-1.19$ \\
\hline & No use & 1.00 & \\
\hline \multirow[t]{2}{*}{ Age } & $<85$ & 1.00 & \\
\hline & $>=85$ & 1.26 & $1.01-1.56$ \\
\hline \multirow[t]{2}{*}{ Sex } & Male & 1.00 & \\
\hline & Female & 0.76 & $0.57-1.03$ \\
\hline \multirow[t]{2}{*}{ Certified level } & $\begin{array}{l}\text { Support } \\
\text { level } 1\end{array}$ & 1.00 & \\
\hline & $\begin{array}{l}\text { Support } \\
\text { level } 2\end{array}$ & 1.47 & $1.17-1.84$ \\
\hline \multirow{2}{*}{$\begin{array}{l}\text { Use of inpatient } \\
\text { medical service }\end{array}$} & Yes & 1.64 & $0.56-4.85$ \\
\hline & No & 1.00 & \\
\hline \multirow{2}{*}{$\begin{array}{l}\text { Use of outpatient } \\
\text { medical service }\end{array}$} & Yes & 0.68 & $0.23-2.01$ \\
\hline & No & 1.00 & \\
\hline \multirow[t]{2}{*}{ Disabled status } & Dependent & 1.12 & $0.90-1.40$ \\
\hline & Independent & 1.00 & \\
\hline \multirow[t]{2}{*}{ Demented status } & Dependent & 2.46 & $1.95-3.11$ \\
\hline & Independent & 1.00 & \\
\hline \multirow[t]{2}{*}{ Household income } & Low & 0.88 & $0.65-1.17$ \\
\hline & $\begin{array}{l}\text { High and } \\
\text { Middle }\end{array}$ & 1.00 & \\
\hline \multirow{4}{*}{$\begin{array}{l}\text { Charlson Comorbidity } \\
\text { Index scores }\end{array}$} & $=0$ & 1.00 & \\
\hline & $>=1$ & 0.85 & $0.65-1.13$ \\
\hline & $>=3$ & 0.99 & $0.72-1.36$ \\
\hline & $>=5$ & 0.92 & $0.61-1.38$ \\
\hline
\end{tabular}


Table 3

Effects of preventive service to avoid deterioration to care level 1 or worse in sub-groups

\begin{tabular}{|c|c|c|c|c|c|}
\hline & & \multicolumn{2}{|c|}{ No adjusted } & \multicolumn{2}{|c|}{ Adjusted* } \\
\hline & & $\mathrm{HR}$ & $95 \% \mathrm{Cl}$ & HR & $95 \% \mathrm{Cl}$ \\
\hline Age $<85$ \& Support level 1 & $(n=494)$ & 1.43 & $0.96-2.13$ & 1.33 & $0.89-1.99$ \\
\hline Age $<85$ \& Support level 2 & $(n=255)$ & 1.00 & $0.64-1.58$ & 1.16 & $0.71-1.88$ \\
\hline Age $>=85 \&$ Support level 1 & $(n=350)$ & 0.63 & $0.43-0.94$ & 0.65 & $0.43-0.97$ \\
\hline Age $>=85 \&$ Support level 2 & $(n=190)$ & 0.76 & $0.47-1.24$ & 0.84 & $0.51-1.39$ \\
\hline
\end{tabular}

\section{Discussion}

In the present study, we analyzed the effects of prevention services to prevent or impede the deterioration in the level of certified care need of LTCI in Japan. The prevention services were effective only in those aged over 85 and needing mild care. In the other groups, use of the prevention service did not maintain the level of certified care needed. Previous studies examined the effects on only specific aged groups, ${ }^{15}$ and did not conduct analysis with varying aged groups. Our results showed the effects of preventive services in comparison with varied age and status of disability.

Our findings indicate that prevention services may not be effective for everyone. Prevention service of LTCI in Japan was initially started as a "preventive care benefit" based on uniform national standards and rewards. From April 2015 onward, the two preventive services (visiting and outpatient care) were transferred to the "Community support program" operated by local governments. For these two services, the financial structure is the same as that for preventive benefit. However, each local government can decide its own standards and rewards. Services can be operated in various forms such as services with more flexible standards and services by residents, including volunteers. For local governments, it is necessary to consider more effective resource allocation in the future when available resources become limited. Our results can allow governments to consider which groups or characteristic segments should be targeted for effective intervention. We demonstrated the potential effects of preventive services for some groups of people. The local government as an insurer of LTCI must identify the groups that may benefit from preventive services in their areas.

Older age was a factor of deterioration in previous studies. ${ }^{1525}$ Especially in some studies with multivariable analysis, older age was a significant factor of deterioration in the adjusted model, ${ }^{15}$ which is consistent with our results in the primary analysis (Table 2). No previous study has analyzed the effects to avoid their deterioration in the older-aged group. In our results, preventive services were effective only in older age and for mildly disabled individuals. This significant effect of prevention 
services seemed to depend on the potential characteristics among those who needed care services for the first time. The subjects aged 85 and over without certification were expected to spend their lives with small disabilities or problems in health. In that group (age > $=85$ and support level 1), there are many persons who are potentially better than those in other groups ${ }^{26}$ Therefore, it seems that this group was likely to have an effect of preventive care.

The strengths of our study are based on using public claim data. Using public administrative data allowed us to follow the entire population of one city, unlike some previous studies that adopted a prepost intervention of the specific groups as their study design. ${ }^{8} 913$ In this study, we collected information on the use of medical services and co-morbidities for adjustment using NHI claim data. Further, we extracted the status of cognitive impairment from the certification survey data, which included the factors of deterioration in the previous analysis. ${ }^{24}$ This variable collection across data became possible only by linking several administrative data between individuals. Our study was the first one to use linked administrative data for evaluating preventive services.

\section{Limitation}

There were four limitations to be considered in the present study. Firstly, we defined the preventive services provided only during the six months after participants' initial certification of LTCI. The effect of preventive service provided at any time was not examined correctly. Therefore, there was some limitation in the time of service provision. We focused on the first duration after first certification because we expected that during this period, their needs would be new, thus motivating them for service use. Even for local government experts, such a duration of service use enables accurately considering subjects' needs.

Second, this study focuses on only one location. Therefore, the effects of the characteristics and resource allocation of the participants based on the location must be considered. However, this study is the first to evaluate preventive services based on the certified level of LTCI using insurance claim data. Our study reveals useful methods and findings for future local government-based interventions.

Third, the first certification of LTCI was defined based on the local government records during the observed period. The individual identification depended on the insured person number that was applied by the local government. The insured person number was changed when the person moved from one location to another. Therefore, it was impossible to identify whether the person had LTCl certification before moving. This limitation also affects the use of the claim data, even if it was nationwide. Such restrictions on individual tracking are difficult unless individual numbers are assigned to each citizen, and the countermeasures will be an issue for future studies.

Fourth, those who used prevention services at least once were included in the exposure group regardless of the frequency, types, or combinations of services, making it difficult to determine whether and how these components contributed to the observed effects. Future research should be conducted to examine the effects of such service usage in details. 
Finally, the effects of unknown confounding cannot be denied. We tried to gather covariates using official data from the local government; nonetheless, there remains the possibility of handling other covariates by linking more existing data. This necessitates future research involving analysis of more covariates for precise results.

\section{Conclusion}

In conclusion, the preventive services of LTCI in Japan showed a significant effect on the deterioration only among subjects aged 85 or older and whose overall support needs were low. To achieve an efficient allocation of limited LTCI resources, it is important for policy makers to identify the population to be targeted for prevention services.

\section{Abbreviations}

LTCl: Long-Term Care Insurance

HR: Hazard Ratio

Cl: Confidence Interval

NHI: National Health Insurance

ID: identification

CCl: Charlson Comorbidity Index

LLC: Limited Liability Company

\section{Declarations}

\section{Ethics approval and consent to participate}

This study was approved by the Medical Ethical Review Board of University of Tsukuba (approved number 1448). As this study was retrospective in design, informed consent was not needed.

\section{Consent for publication}

Not applicable.

\section{Availability of data and materials}

No additional data are available due to data protection requirements. 


\section{Funding}

The study has been supported financed by a grant-in-aid from the Ministry of Health,

Labour and Welfare; Health and Labour Sciences Research Grant, Japan; Comprehensive

Research on Aging and Health (H30-choju-ippan-007) and Statistics and Information (H30-toukei-ippan007). The funder had no role in the design of the study, collection, analysis, or interpretation of data, or in writing the manuscript.

\section{Authors' contributions}

$\mathrm{TI}, \mathrm{TM}, \mathrm{NS}$, and NT contributed in the study design, analysis, and writing of the article. $\mathrm{KI}$ and SY facilitated the collection of the municipality data. All authors critically revised the manuscript and approved the final manuscript.

\section{Competing interests}

Takahiro Mori: The joint appointment as an associate professor at the University of Tsukuba was sponsored by FAST DOCTOR CO., LTD in the 2020 financial year (i.e., April 2020 to the present). FAST DOCTOR CO., LTD has not played any role in the conduct of this study.

The other authors declare no conflict of interest.

\section{Acknowledgments}

We would like to show sincere gratitude to our colleague.in the Health Services Research and Development Center, University of Tsukuba. We also thank Editage (www.editage.jp) for English language editing.

\section{References}

1. Japan Cabinet Office. 2018 White Paper on Aging Society 2019 [Available from: https://www8.cao.go.jp/kourei/whitepaper/w-2018/html/zenbun/s1_1_1.html accessed 2020 Mar 112020.

2. Campbell JC, Ikegami N. Long-term care insurance comes to Japan. Health Aff (Millwood) 2000;19(3):26-39. doi: 10.1377/hlthaff.19.3.26

3. Tamiya $\mathrm{N}$, Noguchi $\mathrm{H}$, Nishi $\mathrm{A}$, et al. Population ageing and wellbeing: lessons from Japan's longterm care insurance policy. Lancet 2011;378(9797):1183-92. doi: 10.1016/s0140-6736(11)61176-8 [published Online First: 2011/09/03] 
4. Ministry of Health, Labour and Wellfare in Japan. Report of Long-term Care Insurance [Available from: https://www.mhlw.go.jp/toukei/list/84-1.html accessed 2020 Mar 112020.

5. Morikawa M. Towards community-based integrated care: trends and issues in Japan's long-term care policy. Int J Integr Care 2014;14:e005. doi: 10.5334/ijic.1066 [published Online First: 2014/02/26]

6. Ministry of Health, Labour and Wellfare in Japan. Campaign of Prevention Care (2016-): Overview [Available from: https://www.mhlw.go.jp/file/06-Seisakujouhou-12300000Roukenkyoku/hukyuutenkai.pdf accessed 2020 Mar 112020.

7. Sakaguchi I. [Investigation and research: Comparison of the effects of power rehabilitation and exercise function improvement services]. Power Rehabilitation 2007;6:148-49.

8. Sakaguchi I, Murai Y, Sato Y, et al. [Effect of Power Rehabilitation in Preventive Benefit: From the Viewpoint of Exercise Function and Degree of Care Required]. Power Rehabilitation 2008;7:168-70.

9. Yanagitake T, Nakamura R, Yamaguchi K, et al. [Preventive benefit using power rehabilitation at facility]. Power Rehabilitation 2007;6:86-87.

10. Yamada R, Yamaguchi Y, Higuchi Y. [Effect of balance training classroom in day care]. Osteoporosis Japan 2009;17(3):540-42.

11. Yokoyama S, Morita S, Nakajima J, et al. [Effect of power rehabilitation on care prevention]. Power Rehabilitation 2007;6:55-57.

12. Karasawa $\mathrm{Y}$, Imai $\mathrm{T}$, Kobayashi $\mathrm{K}$, et al. [Changes in the level of nursing care required for 18 months of continuous outpatient rehabilitation users]. The Gunma Journal of Physical Therapy 2010;21:2027.

13. Kato C, Fujita R, Inoda K. [Temporal changes in physical fitness of participants in the locomotive function improvement program in care prevention outpatient rehabilitation]. Annual Report of Research Institute of Life and Health Sciences 2015;11:25-29.

14. Kikuzawa S, Sawai M, Fujii K, et al. [Effect of use of long-term care insurance service on mildly needing caregivers]. Japanese Journal of Gerontology 2007;29(3):375-83.

15. Kim JN, Shiwaku K. The Effect of Utilization of In-home Services and the Changes in Levels of Care Needs of Frail Persons (2002-2004): Results of a Two-year Follow-up Study. J Rural Med 2012;7(1):614. [published Online First: 2012/01/01 00:00]

16. Matsumoto T, Nekota $Y$. [Analysis of the effect of using the long-term care insurance service on prevention of deterioration in care need level among certified care support level or care need level 1]. Journal of Health and Welfare Statistics 2009;56(10):20-26.

17. Adomi M, Iwagami M, Kawahara $\mathrm{T}$, et al. Factors associated with long-term urinary catheterisation and its impact on urinary tract infection among older people in the community: a population-based observational study in a city in Japan. BMJ Open 2019;9(6):e028371. doi: 10.1136/bmjopen-2018028371 [published Online First: 2019/06/22]

18. Mori T, Hamada $S$, Yoshie $S$, et al. The associations of multimorbidity with the sum of annual medical and long-term care expenditures in Japan. BMC Geriatr 2019;19(1):69. doi: 10.1186/s12877019-1057-7 [published Online First: 2019/03/08] 
19. Hamada S, Takahashi H, Sakata N, et al. Household Income Relationship With Health Services Utilization and Healthcare Expenditures in People Aged 75 Years or Older in Japan: A PopulationBased Study Using Medical and Long-term Care Insurance Claims Data. J Epidemiol 2019;29(10):377-83. doi: 10.2188/jea.JE20180055 [published Online First: 2018/09/27]

20. Iwagami M, Taniguchi $Y$, Jin $X$, et al. Association between recorded medical diagnoses and incidence of long-term care needs certification: a case control study using linked medical and long-term care data in two Japanese cities. Annals of Clinical Epidemiology 2019;1(2):56-68.

21. Ikegami N. Rationale, Design and Sustainability of Long-Term Care Insurance in Japan - In Retrospect. Social Policy and Society 2007;6(03):12.

22. Charlson ME, Pompei P, Ales KL, et al. A new method of classifying prognostic comorbidity in longitudinal studies: development and validation. J Chronic Dis 1987;40(5):373-83. doi:

10.1016/0021-9681(87)90171-8 [published Online First: 1987/01/01]

23. Quan H, Li B, Couris CM, et al. Updating and validating the Charlson comorbidity index and score for risk adjustment in hospital discharge abstracts using data from 6 countries. Am J Epidemiol 2011;173(6):676-82. doi: 10.1093/aje/kwq433 [published Online First: 2011/02/19]

24. Mizuho Information and Research Institute I. Investigation of the feasibility in the model predicting changes in the certified level of long-term care insurance using the certification survey data and claim data, 2019.

25. Kimura A, Ishida Y, Hayashi T, et al. Estimating time of death based on the biological clock. Int J Legal Med 2011;125(3):385-91. doi: 10.1007/s00414-010-0527-4 [published Online First: 2010/11/12]

26. Rothman KJ, Greenland S, Lash TL. Modern Epidemiology Third Edition. Philadelphia, USA: Lippincott Williams \& Wilkins 2008.

\section{Figures}




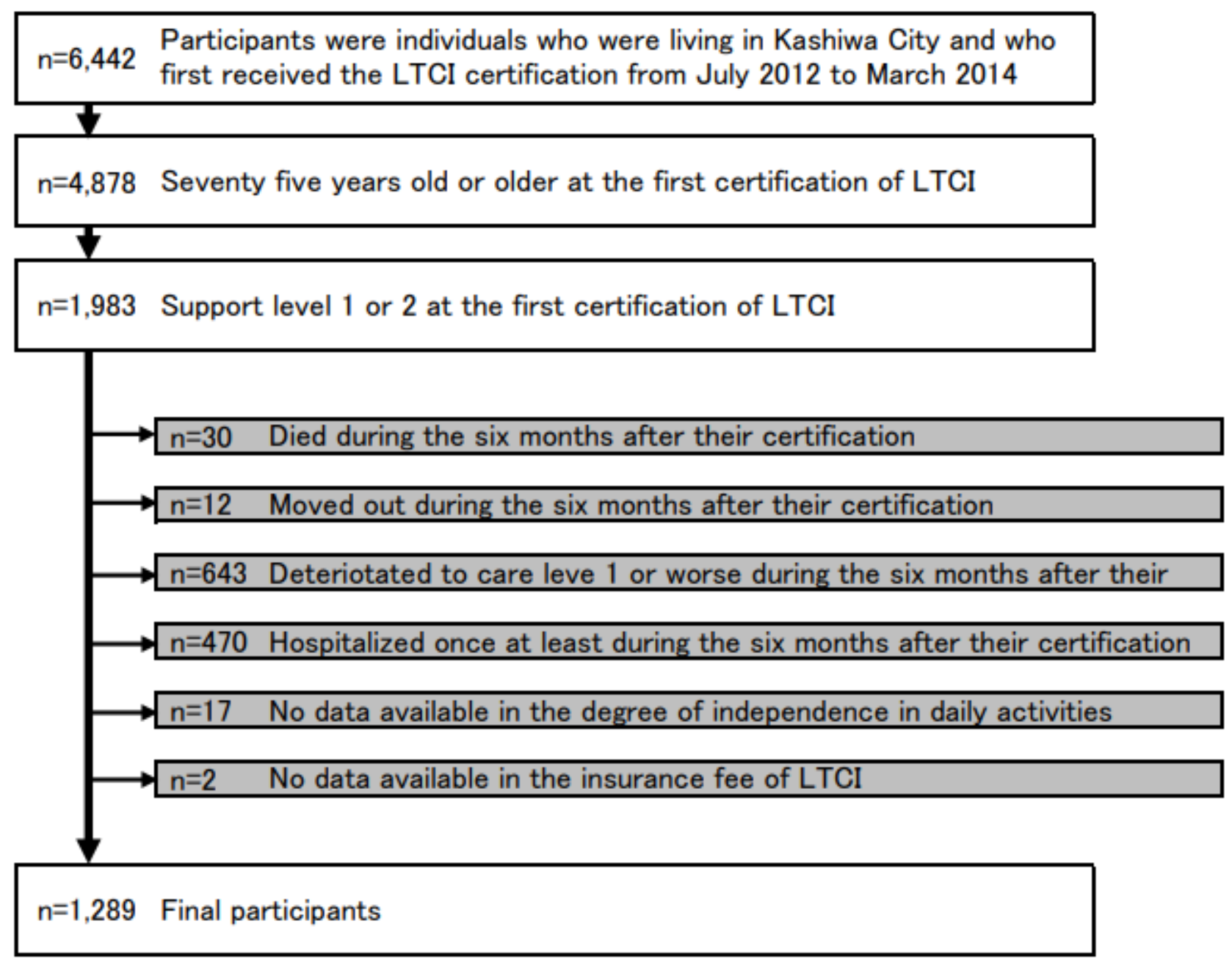

Figure 1

Participants flow 


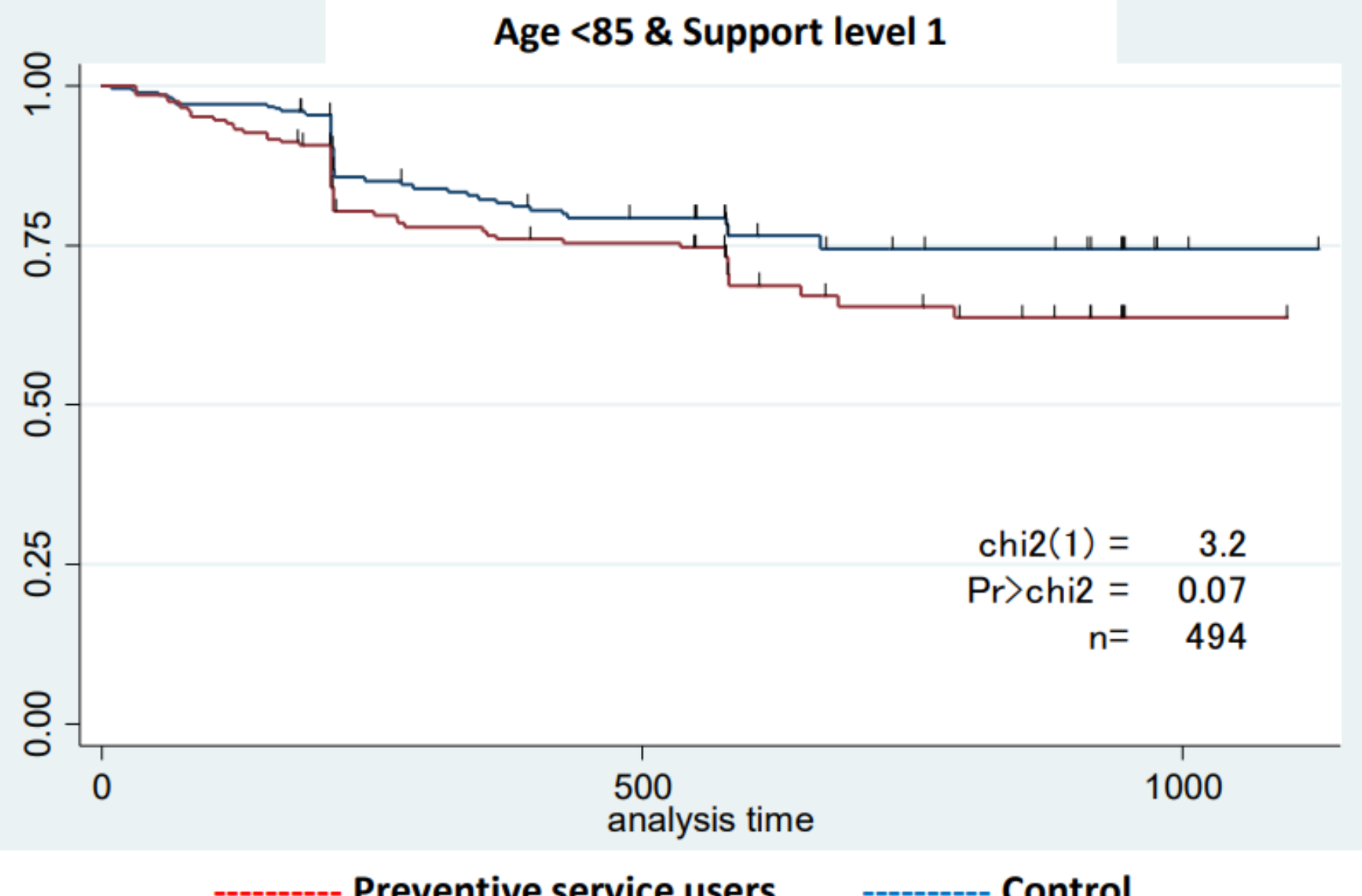

Figure 2

Survival curves of deterioration to care level or worse in preventive services users and control in subgroups

\section{Supplementary Files}

This is a list of supplementary files associated with this preprint. Click to download.

- Appendix1.docx 